(6) OPEN ACCESS
For numbered affiliations see end of article.

\section{Correspondence to}

Dr Alessandro Marinaccio, Epidemiology Unit, Occupational and Environmental Medicine, Epidemiology and Hygiene Department, Italian National Workers Compensation Authority (INAIL), Rome 00143, Italy; a.marinaccio@inail.it

Received 28 September 2016 Revised 4 September 2017 Accepted 5 October 2017 Published Online First 21 December 2017
Check for updates

\footnotetext{
To cite: Marinaccio $A$, Corfiati M, Binazzi A, et al. Occup Environ Med 2018:75:254-262.
}

\title{
The epidemiology of malignant mesothelioma in women: gender differences and modalities of asbestos exposure
}

\author{
Alessandro Marinaccio, ${ }^{1}$ Marisa Corfiati, ${ }^{1}$ Alessandra Binazzi, ${ }^{1}$ Davide Di Marzio, ${ }^{1}$ \\ Alberto Scarselli, ${ }^{1}$ Pierpaolo Ferrante, ${ }^{1}$ Michela Bonafede, ${ }^{1}$ Marina Verardo, ${ }^{2}$ \\ Dario Mirabelli, ${ }^{3}$ Valerio Gennaro, ${ }^{4}$ Carolina Mensi, ${ }^{5}$ Gert Schallemberg, ${ }^{6}$ \\ Guido Mazzoleni, ${ }^{7}$ Enzo Merler, ${ }^{8}$ Paolo Girardi, ${ }^{8}$ Corrado Negro, ${ }^{9}$ Flavia D'Agostin, ${ }^{9}$ \\ Antonio Romanelli, ${ }^{10}$ Elisabetta Chellini, ${ }^{11}$ Stefano Silvestri, ${ }^{12}$ Cristiana Pascucci, ${ }^{13}$ \\ Roberto Calisti, ${ }^{13}$ Fabrizio Stracci, ${ }^{14}$ Elisa Romeo, ${ }^{15}$ Valeria Ascoli, ${ }^{16}$ Luana Trafficante, ${ }^{17}$ \\ Francesco Carrozza, ${ }^{18}$ Italo Francesco Angelillo, ${ }^{19}$ Domenica Cavone, ${ }^{20}$ \\ Gabriella Cauzillo, ${ }^{21}$ Federico Tallarigo, ${ }^{22}$ Rosario Tumino, ${ }^{23}$ Massimo Melis, ${ }^{24}$ \\ Sergio lavicoli, ${ }^{1}$ ReNaM Working Group
}

\section{ABSTRACT}

Introduction The epidemiology of gender differences for mesothelioma incidence has been rarely discussed in national case lists. In Italy an epidemiological surveillance system (ReNaM) is working by the means of a national register.

Methods Incident malignant mesothelioma (MM) cases in the period 1993 to 2012 were retrieved from ReNaM. Gender ratio by age class, period of diagnosis, diagnostic certainty, morphology and modalities of asbestos exposure has been analysed using exact tests for proportion. Economic activity sectors, jobs and territorial distribution of mesothelioma cases in women have been described and discussed. To perform international comparative analyses, the gender ratio of mesothelioma deaths was calculated by country from the WHO database and the correlation with the mortality rates estimated.

Results In the period of study a case list of 21463 MMs has been registered and the modalities of asbestos exposure have been investigated for 16458 (76.7\%) of them. The gender ratio (F/M) was 0.38 and $0.70(0.14$ and 0.30 for occupationally exposed subjects only) for pleural and peritoneal cases respectively. Occupational exposures for female MM cases occurred in the chemical and plastic industry, and mainly in the non-asbestos textile sector. Gender ratio proved to be inversely correlated with mortality rate among countries.

Conclusions The consistent proportion of mesothelioma cases in women in Italy is mainly due to the relevant role of non-occupational asbestos exposures and the historical presence of the female workforce in several industrial settings. Enhancing the awareness of mesothelioma aetiology in women could support the effectiveness of welfare system and prevention policies.

\section{INTRODUCTION}

Malignant mesothelioma (MM) is a highly lethal tumour arising from the pleura and, less frequently,

\section{What this paper adds}

- Malignant mesothelioma is a rare tumour prevalently due to occupational and environmental exposure to asbestos and the attributable fraction to known sources of asbestos exposure in women is generally much lower than in men;

- In Italy a permanent surveillance system for mesothelioma incidence (ReNaM) is active with 21463 collected cases in the period between 1993 and 2012 and 16458 (76.7\%) of them investigated for exposure;

- In ReNaM, gender ratio (F/M) is 0.38 and 0.70 ( 0.14 and 0.30 in the occupational exposed subjects subgroup) for pleural and peritoneal forms respectively;

- Italy presents a larger presence of women among mesothelioma cases due to the relevance of non-occupational exposures and to the historically high female workforce participation in several industrial settings (mainly non-asbestos textile sector);

- The awareness of occupational or environmental origin of mesothelioma in women could improve the efficiency of the public compensation system and the prevention policies, redefining the tools for investigating asbestos exposure in a gender perspective.

from the peritoneal and pericardial serous membranes, or from the tunica vaginalis of testis. The causal association with asbestos exposure has been demonstrated so far and the International Agency for Research on Cancer confirmed that all forms of asbestos (amphiboles as actinolite, amosite, anthophyllite, crocidolite, tremolite and serpentine as chrysotile) are carcinogenic for humans (group 1) 
causing mesothelioma, as well as lung, larynx and ovary cancer. Positive associations have been also observed between exposure to all forms of asbestos and pharynx, stomach and colorectal cancers. $^{1}$

Due to its high tensile strength and thermal and chemical resistance, asbestos has been intensively used in a number of industrial applications between the 1950s and the 1980s in almost all Western countries and, at present, it is still freely extracted and processed in many countries of Asia, South America, Africa and in the former Soviet Union. ${ }^{23}$

In Italy, up to the asbestos ban in 1992 about 3748550 tons of raw asbestos was mined, with a peak production of more than 160000 tons/year in the period between 1976 and 1980. While in countries such as the USA, UK and the Nordic European countries asbestos consumption levelled off during the 1960 s and 1970 s and then rapidly decreased, in Italy it began to decline some 10 to 20 years afterwards. ${ }^{4}$

The fraction of MM cases attributable to asbestos exposure in women was always estimated to be much lower than in men, despite a certain variability among published studies. ${ }^{5}$ In environmentally exposed subjects the male to female ratio has been reported as about 1.2-1.4. ${ }^{67}$

Gender differences have not been deeply analysed for incidence of mesothelioma cases ${ }^{8-10}$ and in few studies asbestos exposure has been compared by gender in national case lists, ${ }^{11} 12$ whereas most data comes from epidemiological studies conducted in environmentally exposed populations ${ }^{67}$ and from case series analysis. ${ }^{13}{ }^{14}$ A gender gap in the efficiency of exposure definition methods has also been suggested, leading to a still limited knowledge about the actual role of asbestos exposure in $\mathrm{MM}$ among women ${ }^{8}$ and to a lower rate of compensation as well. ${ }^{15} 16$

In Italy a permanent MM epidemiological surveillance system is working based on a national MM Register (Registro Nazionale dei Mesoteliomi, ReNaM in Italian). ReNaM is devoted to provide estimates of the incidence of malignant mesothelioma, to define and record asbestos exposures, to assess the impact of the disease at the population level and to identify any possible underestimated or unknown source of asbestos contamination. ReNaM regularly publishes figures for epidemiology and asbestos exposure of mesothelioma ill subjects. ${ }^{417}$

The main purposes of this study are to study the gender ratio among MM cases registered by ReNaM and to assess the specific patterns of incidence and asbestos exposure in women. Moreover, mortality data will be used to compare the internationally gender ratio of mesothelioma among countries.

\section{METHODS}

\section{ReNaM}

$\mathrm{ReNaM}$ is an epidemiological surveillance system characterised by a network of regional operating centres (Centri Operativi Regionali in Italian - COR), gradually established in all 20 Italian regions. Case lists from three Italian regions (Calabria, Sardinia and Molise) cannot be considered complete yet. CORs actively search and register incident cases of malignant mesothelioma from healthcare services that diagnose and treat cases (especially pathology and histology units, pulmonology and chest surgery wards). At each COR an expert physician classifies MM cases in three categories according to the level of diagnostic certainty: certain (with cyto-histological confirmation); probable (with not definitive cytological or histological examination); and possible mesothelioma (with radiological and clinical evidence only). The MM diagnosis coding system adopted in ReNaM is extensively described elsewhere. ${ }^{18} 19$ Occupational history, lifestyle habits and residential history are reconstructed using a standardised questionnaire administered by a trained interviewer to the MM cases or to their next of kin and confirmed through cooperation with public local health and safety agencies. In each COR an industrial hygienist or a panel of industrial hygienists classifies and encodes the asbestos exposure, according to the ReNaM guidelines. ${ }^{18}$ CORs periodically transmit the registered data to ReNaM that provides epidemiological analyses, publish national reports and promotes specific research projects. ${ }^{20}$

To date, ReNaM has collected cases with a diagnosis of malignant mesothelioma in the period 1993 to 2012. Pleural, peritoneal and pericardial MM cases are extracted and analysed for the whole available period. Standardised incidence rates for 2011 (more recent year with complete incidence data) have been calculated, using direct methods and the Italian population at the 2010 census as reference for standardisation. Latency period has been estimated as the time elapsing from the beginning of exposure to diagnosis. Associations between gender and age class at diagnosis, period of diagnosis, level of diagnostic certainty, morphology and type of asbestos exposure are investigated for each anatomical site separately. At this purpose gender ratio, defined as female to male ratio $(\mathrm{F} / \mathrm{M})$, for each modality of the above mentioned variables, has been compared with the overall value, by using the exact test for single proportions (likewise for ratios and rates) if cell frequencies were lower than five and the normal approximated test, corrected for continuity, if frequencies were higher than five. ${ }^{21}$

Incident cases of malignant mesothelioma in women attributed to occupational asbestos exposure are analysed by activity sector and job. For each case exposures with the highest level of likelihood as coded by CORs' expert hygienists were considered and multiple exposures with the same likelihood level (but occurring in different sectors or in different jobs within the same sector) were taken and analysed separately. Only sectors with at least $20 \mathrm{MM}$ cases in women are presented and for each sector the most frequent five jobs are reported. The $\mathrm{F} / \mathrm{M}$ ratio for the considered occupational sectors has been also calculated.

Only for Italian regions collecting incidence data, as specified above, the territorial distribution of female mesothelioma cases according to municipality of residence at diagnosis is mapped. The crude rates have been calculated for the Italian municipalities with at least one mesothelioma case in female residents $(n=1889)$, considering the cumulative population during the incidence period between 1993 and 2012 as denominator. Because of the extreme territorial details, no standardisation of incidence data is performed and the incident cases are simply divided for the general resident population (according to person-years of observation). Only for municipalities with more than eight female incident cases in the considered period and a crude rate higher than four per 100000 inhabitants the predominant modalities of exposure (occupational, environmental or familial) are labelled. Furthermore, where occupational asbestos exposures are predominant the economic activity sector with the greatest number of cases is indicated.

\section{International comparative analyses of mortality data}

National figures on mesothelioma incidence are too few to admit international comparisons. With the scope to perform international comparative analyses, we extracted therefore the numbers of deaths for malignant mesothelioma (ICD-10 category C45) from the WHO mortality database (www.who.int/healthinfo/ mortality_data). Data referring to 2011 have been selected 
because it was the most recent year with availability of data for a sufficient number of countries and only countries with at least 20 mesothelioma deaths in both genders are included in the analysis. Standardised mortality rates are calculated after retrieving resident population for all countries from the WHO database and considering world population as reference (WHO mortality database available at www.who.int/healthinfo/mortality_data). Gender ratio for all countries as the ratio between the number of female and male MM deaths (F/M) has been calculated and plotted as a dispersion graph with mortality rates. Different regression curves have been tested to identify the best predictor model according to goodness of fit $\left(\mathrm{R}^{2}\right)$.

For all statistical analyses we used SAS, version 9.3 (SAS Institute Inc., Cary, NC, USA), and IBM-SPSS, version 22.0 (IBM SPSS, Armonk, New York, USA) packages for statistical analysis.

\section{RESULTS}

\section{ReNaM}

In the period between 1993 and 2012 a case list of $21463 \mathrm{MM}$ has been collected with a national standardised incidence rate for pleural forms in 2011 of 3.64 (per 100000 person-years) in men and 1.32 in women. Pleural site is reported in 93.3\% (19 955 cases) of recorded MM cases: peritoneal and pericardial cases represent $6.5 \%$ (1392 cases) and $0.3 \%$ (51 cases) of the whole caselist respectively. In the ReNaM archive there were recorded 65 cases of mesotheliomas of tunica vaginalis of testicular site, which have been excluded from the analyses. Data presented are therefore referring to a total of $21398 \mathrm{MM}$ cases (6087 women and 15311 men; overall $F / M=0.40)$. The gender ratio $(F / M)$ is $0.38,0.70$ and 0.46 for pleural, peritoneal and pericardial cases respectively (table 1 ). The number of female pleural MMs is proportionally higher in the oldest group of cases $(\geq 85$ years' old): it remains unchanged in the whole period of observation (1993-2012). Gender ratio is lower than the overall value for the pleural cases with histological confirmation and for cases with fibrous or biphasic morphology. The modalities of asbestos exposure have been investigated for 16458 mesothelioma cases $(76.9 \%)$. This percentage is not consistent across regions but shows a great territorial variability (higher than $90 \%$ in Lombardy, Tuscany, Apulia, Umbria, Veneto, Bolzano and Trento provinces: lower than $50 \%$ in Sicily, Campania and Calabria). The availability of exposure information was also different by gender $(78.9 \%$ in men and $71.9 \%$ in women). In the $52 \%$ of cases investigated for exposure $(\mathrm{n}=8561)$, the interview has been

Table 1 Main characteristics of malignant mesothelioma cases $(n=21,398)$ collected by the Italian national mesothelioma register (ReNaM) by cancer site and gender. Italy, incidence period: 1993-2012

\begin{tabular}{|c|c|c|c|c|c|c|c|c|c|}
\hline & \multicolumn{3}{|l|}{ Pleural } & \multicolumn{3}{|c|}{ Peritoneal } & \multicolumn{3}{|c|}{ Pericardial } \\
\hline & Females & Males & F/M & Females & Males & $\mathrm{F} / \mathrm{M}$ & Females & Males & F/M \\
\hline \multicolumn{10}{|l|}{ Age classes } \\
\hline$\leq 44$ & 100 & 213 & 0.47 & 39 & 52 & 0.75 & 1 & 6 & 0.17 \\
\hline $45-64$ & 1375 & 4281 & $0.32^{*}$ & 203 & 284 & 0.71 & 6 & 10 & 0.60 \\
\hline $65-84$ & 3516 & 9182 & 0.38 & 314 & 467 & 0.67 & 8 & 19 & 0.42 \\
\hline$\geq 85$ & 505 & 783 & $0.64^{*}$ & 19 & 14 & 1.36 & 1 & - & - \\
\hline \multicolumn{10}{|l|}{ Period of diagnosis } \\
\hline 1993-1997 & 533 & 1511 & 0.35 & 66 & 93 & 0.71 & 3 & 5 & 0.60 \\
\hline 1998-2002 & 1381 & 3610 & 0.38 & 144 & 189 & 0.76 & 6 & 13 & 0.46 \\
\hline 2003-2007 & 1826 & 4712 & 0.39 & 192 & 271 & 0.71 & 5 & 7 & 0.71 \\
\hline 2008-2012 & 1756 & 4626 & 0.38 & 173 & 264 & 0.66 & 2 & 10 & 0.20 \\
\hline \multicolumn{10}{|l|}{ Diagnostic certainty } \\
\hline MM certain & 4144 & 11705 & $0.35^{*}$ & 473 & 685 & 0.69 & 12 & 27 & 0.44 \\
\hline MM probable & 660 & 1329 & $0.50^{*}$ & 81 & 85 & $0.95^{*}$ & 2 & 7 & 0.29 \\
\hline MM possible & 692 & 1425 & $0.49^{*}$ & 21 & 47 & 0.45 & 2 & 1 & 2.00 \\
\hline \multicolumn{10}{|l|}{ Morphology } \\
\hline Epithelioid & 3038 & 7733 & 0.39 & 301 & 478 & 0.63 & 5 & 12 & 0.42 \\
\hline Fibrous & 313 & 1244 & $0.25^{*}$ & 21 & 31 & 0.68 & 2 & 3 & 0.67 \\
\hline Bifphasic & 513 & 1654 & $0.31^{*}$ & 72 & 65 & $1.11^{*}$ & 4 & 5 & 0.80 \\
\hline MM NOS & 683 & 1805 & 0.38 & 141 & 154 & $0.92^{*}$ & 3 & 11 & 0.27 \\
\hline Not available & 949 & 2023 & $0.47^{*}$ & 40 & 89 & $0.45^{*}$ & 2 & 4 & 0.50 \\
\hline \multicolumn{10}{|l|}{ Asbestos exposuret } \\
\hline Occupational & 1321 & 9525 & $0.14^{*}$ & 132 & 444 & $0.30 *$ & 4 & 18 & 0.22 \\
\hline Non-occupational & 1151 & 492 & $2.34^{*}$ & 75 & 27 & $2.78^{*}$ & 1 & - & - \\
\hline Familial & 632 & 106 & $5.96^{*}$ & 43 & 4 & $10.75^{*}$ & - & - & - \\
\hline Environmental & 368 & 285 & $1.29^{*}$ & 24 & 16 & $1.50^{*}$ & 1 & - & - \\
\hline Leisure activities & 151 & 101 & $1.50^{*}$ & 8 & 7 & 1.14 & - & - & \\
\hline $\begin{array}{l}\text { Unknown, not } \\
\text { probable }\end{array}$ & 1497 & 1450 & $1.03^{*}$ & 184 & 124 & $1.48^{*}$ & 9 & 4 & $2.25^{*}$ \\
\hline Total & 3969 & 11467 & 0.35 & 391 & 595 & 0.66 & 14 & 22 & 0.64 \\
\hline Not available & 1527 & 2992 & 0.51 & 184 & 222 & 0.83 & 2 & 13 & 0.15 \\
\hline Overall & 5496 & 14459 & 0.38 & 575 & 817 & 0.70 & 16 & 35 & 0.46 \\
\hline
\end{tabular}

*Gender ratio significantly different from the overall value $(p<0.05)$.

†Asbestos exposure is available for $16458 \mathrm{MM}$ cases. 
conducted directly with the affected person, but this percentage is lower in women $(45.9 \%)$ than in men $(54.2 \%)$. We found that $86.9 \%$ of male mesothelioma incident cases, for which the assessment of exposure has been completed, had been exposed to asbestos (61.4\% for female cases) and $95 \%$ out of them were occupationally exposed (54.3\% for female cases). Among occupationally exposed MM cases the gender ratio is equal to 0.14 and 0.30 for pleural and peritoneal forms respectively. Pleural and peritoneal MM cases of non-occupational origin (familial, environmental and leisure time circumstances) show an $\mathrm{F} / \mathrm{M}$ ratio significantly higher than occupational cases but similar to the one observed in unknown or improbable asbestos exposed cases (table 1). No significant temporal trend is found in exposure pattern as well as in age distribution by gender (data not presented in detail).
For pleural MM, mean age at diagnosis is higher in women than in men among cases either with occupational or non-occupational exposure (70.5 vs 68.8 years and 69.3 vs 66.4 years respectively). Within the latter group the difference in age at diagnosis is mostly evident in familial cases (68.9 years in women vs 64.2 in men), but not significant in environmental and leisure time exposed (data not presented in detail). Latency lasts 50.5 $(\mathrm{SD}=12.5)$ years on average for pleural female cases occupationally exposed but $47.9 \pm 11.1$ years in men, whereas it is very similar in peritoneal cases between genders $(46.0 \pm 11.8$ and $45.7 \pm 10.5$ for female and male occupational $\mathrm{MM}$ cases respectively). Occupational exposures for female mesothelioma incident cases occurred in a large number of economic sectors including the asbestos industry, but also other industrial settings, such as the chemical and plastic industry, and mainly

Table 2 Economic sectors, jobs involved in asbestos exposure and gender ratio value (F/M) for malignant mesothelioma cases in women. Italy, 1993-2012, Italian national mesothelioma register. Only economic sectors with 20 exposures or more; only 5 (and equal) most frequent jobs

\begin{tabular}{|c|c|c|}
\hline Economic sector & Jobs (number of exposures) & $\begin{array}{l}\text { Gender ratio } \\
(\mathrm{F} / \mathrm{M})\end{array}$ \\
\hline $\begin{array}{l}\text { Textile industry (no asbestos direct use) } \\
\text { (528 exposures) }\end{array}$ & $\begin{array}{l}\text { INDUSTRIAL WEAVER (90); MECHANICAL LOOM OPERATOR FOR CLOTHES AND BRAID MAKING (46); LABOURERS AND } \\
\text { OTHER UNSKILLED INDUSTRIAL WORKERS (44); WINDING-MACHINE OPERATOR (40); AUTOMATIC WEAVING MACHINE } \\
\text { OPERATOR (35) }\end{array}$ & $1.27^{*}$ \\
\hline Manufacture of wearing apparel (97) & $\begin{array}{l}\text { TAILOR (46); DRESSMAKER TAILOR (8); TAILORS, HANDICRAFT CUTTERS, PATTERN-MAKERS AND HATTERS (6); } \\
\text { LABOURERS AND OTHER UNSKILLED INDUSTRIAL WORKERS (6); UNDERGARMENT SEWER (5); PRESS OPERATOR (5); } \\
\text { INDUSTRIAL GARMENT SEWING MACHINE OPERATOR (5) }\end{array}$ & $2.77^{*}$ \\
\hline Health and social work (94) & $\begin{array}{l}\text { HAIRDRESSER (22); DRY CLEAN AND LAUNDRY PRESSER (12); HAND IRONER (10); PRESS OPERATOR (10); OPERA } \\
\text { SINGER (3); CLOAKROOM ATTENDANT (3); HEALTHCARE AUXILIARY ASSISTANT (3) }\end{array}$ & $0.51^{*}$ \\
\hline Asbestos-cement industry (79) & $\begin{array}{l}\text { ASBESTOS-CEMENT WORKER (49); CONCRETE MIXER MACHINE OPERATOR (5); CEMENT AND OTHER MINERAL } \\
\text { PRODUCTS MACHINE OPERATOR (4); WAGES AND SALARIES CLERK (3); OFFICE CLERK (2); GRINDING, MILLING AND } \\
\text { MIXING MACHINE OPERATOR (2); CEMENT PIPE FITTER (2) }\end{array}$ & 0.20 \\
\hline $\begin{array}{l}\text { Food and beverages industry (except } \\
\text { sugar manufacture) (79) }\end{array}$ & $\begin{array}{l}\text { LABOURERS AND OTHER UNSKILLED INDUSTRIAL WORKERS (8); OTHER HANDICRAFT AND INDUSTRIAL FOOD } \\
\text { PROCESSING WORKERS (6); CHEESE RIPENER (INDUSTRIAL DIARY PRODUCTS MAKER) (3); STORE SALESPERSON (3); } \\
\text { HANDICRAFT AND INDUSTRIAL FOOD PROCESSING WORKERS (3) FOOD INDUSTRY MACHINE-OPERATORS (3) }\end{array}$ & 0.34 \\
\hline $\begin{array}{l}\text { Manufacture of machinery and } \\
\text { equipment (79) }\end{array}$ & $\begin{array}{l}\text { LABOURERS AND OTHER UNSKILLED INDUSTRIAL WORKERS (14); HANDICRAFT AND INDUSTRIAL METAL } \\
\text { ENGINEERING WORKERS (9); WELDER (3); ELECTRICAL AND ELECTRONIC EQUIPMENT ASSEMBLERS, REPAIRERS AND } \\
\text { SERVICERS (EXCEPT PRODUCTION LINE WORKERS)(3); OTHER GENERAL OFFICE CLERICAL WORKERS (3) }\end{array}$ & 0.07 \\
\hline Asbestos textile industry (72) & $\begin{array}{l}\text { SPINNING MACHINE-OPERATOR (25); LABOURERS AND OTHER UNSKILLED INDUSTRIAL WORKERS (16); MECHANICAL } \\
\text { LOOM OPERATOR FOR CLOTHES AND BRAID MAKING (7); INDUSTRIAL WEAVER (4); WEAVER OF SPECIAL TISSUES (4) }\end{array}$ & $3.08^{*}$ \\
\hline Agriculture and farming of animals (60) & FARMER (20); FARM HAND (12); FIELD CROP FARM WORKERS (7); FARMERS AND FARM WORKERS (4) & 0.27 \\
\hline Wholesale and retail trade (58) & $\begin{array}{l}\text { RAG COLLECTOR (8); SORTER (6); RETAILER (5); OTHER GENERAL OFFICE CLERICAL WORKERS (4); RAGMAN (4); } \\
\text { SALESMAN AND SIMILAR JOBS (4); STORE SALESPERSON (4) }\end{array}$ & 0.17 \\
\hline $\begin{array}{l}\text { Manufacture of chemical and plastic } \\
\text { products (54) }\end{array}$ & $\begin{array}{l}\text { LABOURERS AND OTHER UNSKILLED INDUSTRIAL WORKERS (17); OTHER GENERAL OFFICE CLERICAL WORKERS } \\
\text { (2); CHEMICAL PROCESSING PLANT WORKER (2); OFFICE CLERKS (2); PACKING MACHINE-OPERATOR (2); OTHER } \\
\text { AUXILIARY PERSONNEL OF PRODUCTS PACKAGING, STORAGE AND DELIVERY (2); CHEMICAL, PETROLEUM } \\
\text { REFINING AND CEMENT PRODUCTION PLANT OPERATOR (2); SPINNING AND SPOOLING MACHINE-OPERATOR (2); } \\
\text { PHARMACEUTICAL- AND TOILETRY-PRODUCTS MACHINE OPERATOR (2); OTHER CHEMICAL PROCESSING PLANT } \\
\text { OPERATOR (2) }\end{array}$ & 0.11 \\
\hline Rubber industry (49) & $\begin{array}{l}\text { LABOURERS AND OTHER UNSKILLED INDUSTRIAL WORKERS (14); RUBBER PRODUCTS MOULDER (5); OTHER RUBBER } \\
\text { PRODUCTS PROCESSING OPERATOR (5); INDUSTRIAL QUALITY CONTROL TECHNICIAN (2); RUBBER MIXER (2); } \\
\text { RUBBER ROLLING PRESS OPERATOR (2); INDUSTRIAL PLANT OPERATOR (2) }\end{array}$ & 0.36 \\
\hline $\begin{array}{l}\text { Other manufacturing industries } \\
\text { (furniture, jewellery, musical } \\
\text { instruments, sport goods, etc.) (43) }\end{array}$ & JEWELLERY AND PRECIOUS-METAL WORKER (10) OFFICE CLERK (3); WELDER (2); GOLD POLISHER (2) & 0.19 \\
\hline Glass and ceramics production (42) & $\begin{array}{l}\text { LABOURERS AND OTHER UNSKILLED INDUSTRIAL WORKERS (6); GLASS MAKERS, CUTTERS, GRINDERS AND FINISHERS } \\
\text { (5); GLASS AND PORCELAIN DECORATIVE PAINTER (3); OTHER AUXILIARY PERSONNEL OF PRODUCTS PACKAGING, } \\
\text { STORAGE AND DELIVERY (3); GLASS PRODUCTS SORTER (2); GLAZIER (2); POTTERS, FLASK BLOWERS, CUP-FORMERS } \\
\text { AND GLASSWORKS WORKERS (2); CERAMIST (2) }\end{array}$ & 0.29 \\
\hline Hotels, restaurants and bars (26) & $\begin{array}{l}\text { COOK (4); DRY CLEAN AND LAUNDRY PRESSER (3); CANTEEN ASSISTANT (2); HOTEL CLEANER (2); HOTEL } \\
\text { CLOAKROOM ATTENDANT AND PRESSER (2); HOTEL AND RESTAURANT COOK (2); PRESS OPERATOR (2) }\end{array}$ & 0.42 \\
\hline Education (22) & $\begin{array}{l}\text { PRIMARY SCHOOL TEACHER (4); TEACHER OF SPORTS, GYMNASTICS, PERSONAL HEALTH (MIDDLE SCHOOL) (3); } \\
\text { SCHOOL PORTER AND SIMILARS (2); TEACHER OF NATURAL SCIENCES (2); HUMANITIES TEACHER (2). }\end{array}$ & $0.54^{*}$ \\
\hline Overall (of reported economic sectors) & & 0.34 \\
\hline
\end{tabular}




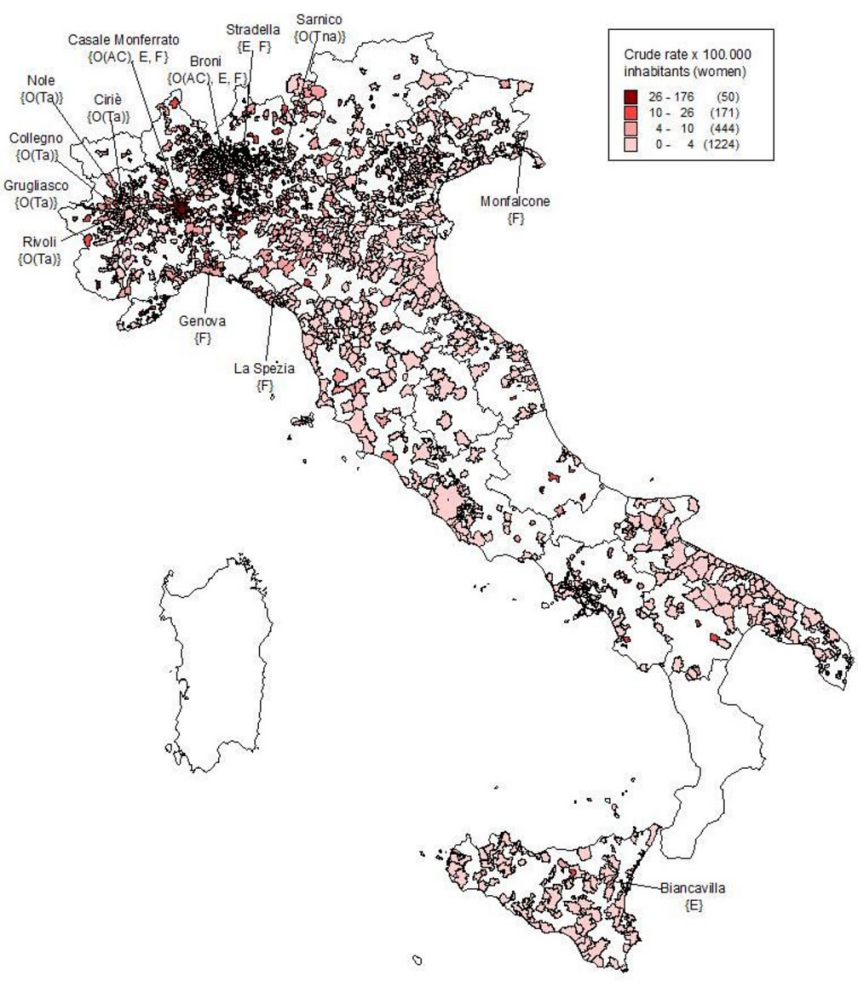

Figure 1 Crude incidence rates ( ${ }^{*} 100000$ inhabitants) for malignant mesothelioma in women by municipalities of residence at diagnosis. Municipalities with significant number of cases and modalities of asbestos exposure in women. Italian national mesothelioma register (ReNaM), Italy, period of incidence 1993-2012. Labels are reported for municipalities with crude incidence rates $>4$ and at least $8 \mathrm{MM}$ female cases with occupational or non-occupational (environmental, familial, leisure activities-related) exposure. Labels show the municipalities and the modalities of asbestos exposure: $\mathrm{O}(\mathrm{Ta}$ ) prevalently occupational exposure in asbestos textile sector; $\mathrm{O}(\mathrm{Tna}$ ) non-asbestos textile; $\mathrm{O}(\mathrm{AC})$ asbestos-cement plant; $\mathrm{O}(\mathrm{S})$ shipbuilding and repair; E environmental exposure; $F$ familial exposure, due to cohabitation with exposed workers.

the non-asbestos textile sector (table 2). The latter was in particular identified as causing asbestos exposure in more than $40 \%$ of both pleural and peritoneal MM female cases of occupational origin. Gender ratio (F/M) of MM cases is higher than one for the textile industry (with or without direct use of asbestos in the industrial cycle: 3.08 and 1.27 respectively) and the garment industry (2.77). Among jobs more frequently causing asbestos exposure in women there are blue-collar workers but also farmers, tailors and dressmakers, ironers, clerks and teachers (table 2).

Looking at the territorial distribution of MM cases recorded by $\mathrm{ReNaM}$, the $\mathrm{F} / \mathrm{M}$ ratio varies among regional case lists from 0.56 to 0.57 (Piedmont, Lombardy) to 0.19 to 0.23 (Liguria, Friuli-Venezia Giulia) reaching the minimum value in Umbria $(0.11)$ but based on a limited number of cases in this region in the 1993 to 2012 period $(n=92)$. Figure 1 shows the territorial map of crude incidence rates for mesothelioma in women. Based on female MM absolute number of cases and crude rate (see selection criteria in Methods for details), 13 municipalities were identified and characterised for exposure modality: Monfalcone $(\mathrm{F} / \mathrm{M}=0.3)$ in Friuli-Venezia Giulia; Genova $(0.2)$ and La Spezia (0.1) in Liguria; Casale Monferrato (0.8), Grugliasco (0.8), Collegno (0.9), Ciriè (1.2), Nole (1.2), Rivoli (0.9) in Piedmont;
Table 3 Number of MM cases, crude incidence rates (*100 000 inhabitants) for malignant mesothelioma in women, gender ratio (F/M) in the 13 Italian municipalities with the highest number of cases. Italy, Italian national mesothelioma register, period of incidence 1993-2012

\begin{tabular}{llll}
\hline & $\begin{array}{l}\text { Number of } \\
\text { cases } \\
\text { In women }\end{array}$ & $\begin{array}{l}\text { Crude incidence } \\
\text { rate in women } \\
(* 100000 \\
\text { inhabitants) }\end{array}$ & $\begin{array}{l}\text { Gender ratio } \\
(\mathrm{F} / \mathrm{M})\end{array}$ \\
\hline CASALicipality & 255 & 71.5 & 0.8 \\
\hline GENOVA & 227 & 4.0 & 0.2 \\
\hline BRONI & 43 & 66.1 & 0.8 \\
\hline COLLEGNO & 39 & 8.5 & 0.9 \\
\hline STRADELLA & 33 & 44.6 & 1.6 \\
\hline LA SPEZIA & 32 & 4.1 & 0.1 \\
\hline GRUGLIASCO & 26 & 6.9 & 0.8 \\
\hline MONFALCONE & 25 & 10.1 & 0.3 \\
\hline RIVOLI & 24 & 4.9 & 0.9 \\
\hline SARNICO & 14 & 35.2 & 1.4 \\
BIANCAVILLA & 13 & 7.5 & 0.9 \\
\hline CIRIĖ & 13 & 7.3 & 1.2 \\
NOLE & 11 & 17.9 & 1.2 \\
\hline
\end{tabular}

Sarnico (1.4), Broni (0.8) and Stradella (1.6) in Lombardy; and Biancavilla (0.9) in Sicily (figure 1 and table 3).

\section{International comparative analyses of mortality data}

When comparing mesothelioma mortality among countries, gender ratio $(\mathrm{F} / \mathrm{M})$ results to be inversely correlated with standardised mortality rate $\left(b=-0.22 ; R^{2}=0.35 ; p<0.001\right)$ in the linear regression model, that presents the highest goodness of fit value among all tested regression models. All considered countries tend to show a linear decrease in $\mathrm{F} / \mathrm{M}$ ratio for increasing mortality rate. In the selected 36 countries, the percentage of female cases among mesothelioma deaths varied from $10.6 \%$ in Denmark to $43.5 \%$ in Turkey, whereas the overall raw mortality rate (both genders) ranged from 3.7 per 100000 cases in the UK to 0.04 in Brazil. Italy shows a pattern with a number of women involved higher than expected according to the model (figure 2).

\section{DISCUSSION}

As a legacy of the massive use of asbestos until the ban in 1992, Italy is today one of the countries suffering most from the occurrence of asbestos-related disease. Thanks to a long-term epidemiological surveillance of MM incidence, which covers almost completely the Italian territory, our study found out that about $28 \%$ of mesotheliomas in Italy occurs among women with a F/M ratio equal to 0.40 which is almost steady over the whole considered incidence period (1993-2012).

Specific surveillance systems comparable for information completeness, exposure assessment and territorial coverage are scarce and, to the best of our knowledge, currently ongoing only in Australia, France and South Korea. ${ }^{22}$ A gender ratio equal to 0.24 female cases for each male case is reported in Australia based on $518 \mathrm{MM}$ cases among men and 123 in women diagnosed in 2014. ${ }^{23}$ The French National Mesothelioma Surveillance Programme (PNSM) currently recording incident MM cases in 26 French geographical districts, accounting for about a quarter of the French population, provides a distribution of $1526 \mathrm{MM}$ incident cases among men and 411 among women in the 1998 to 2008 period $(\mathrm{F} / \mathrm{M}$ ratio $=0.27)$. For mesothelioma female cases without identified asbestos exposure, occurring in 


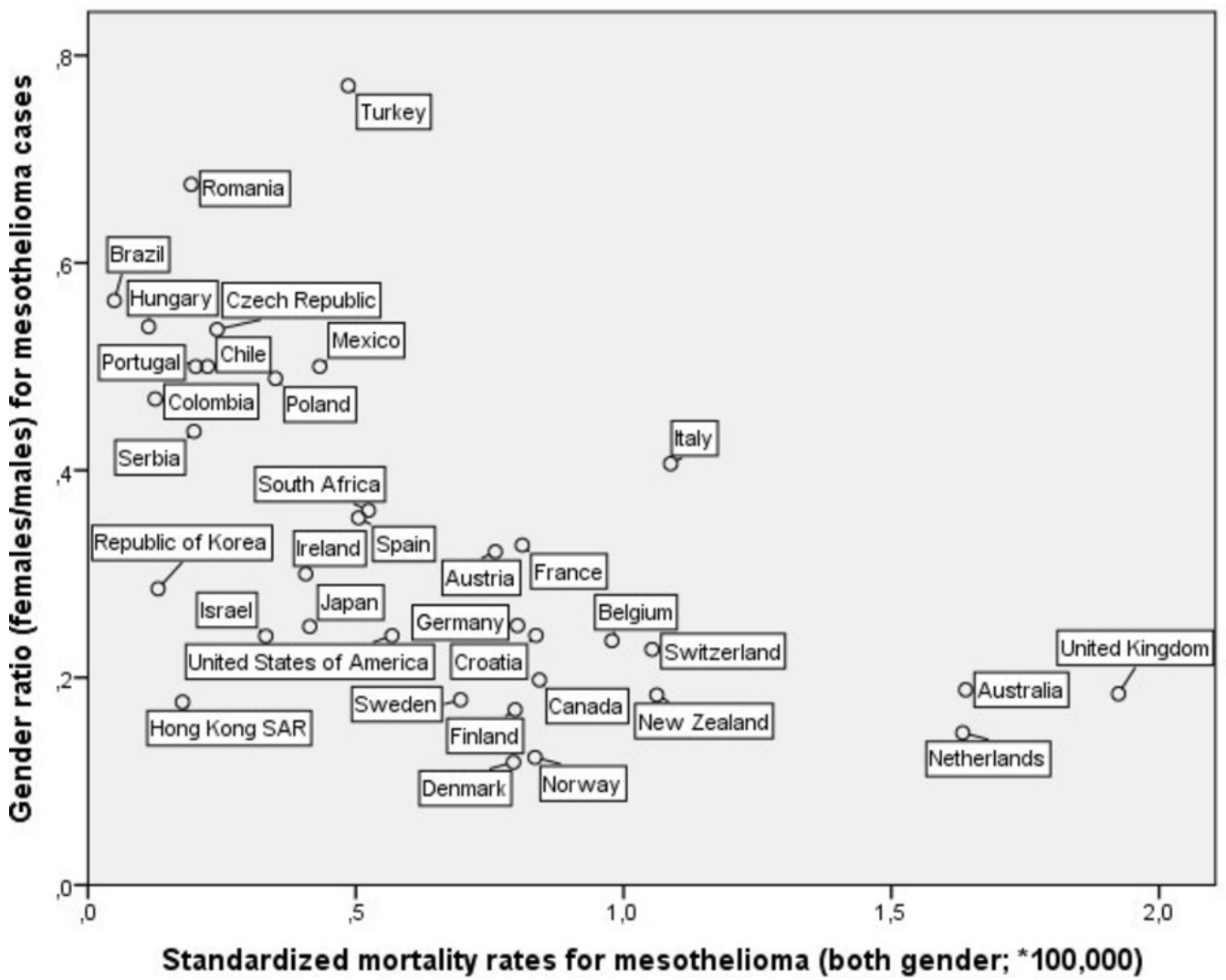

Figure 2 Standardised mortality rates for malignant mesothelioma (both genders) and gender ratio (F/M). Based on 'WHO mortality database', year=2011; only countries with more than 20 cases.

areas with recognised occupational asbestos exposure in males, environmental contamination has been advocated as a reasonable explanation for exposure. ${ }^{8}$ This hypothesis seems supported by the findings of an exploratory analysis of 318 female malignant pleural mesothelioma cases recorded by the French surveillance system between 1998 and 2009, suggesting a relevant causal contribution of non-occupational asbestos exposure (para-occupational and environmental exposure) in those women never occupationally exposed. ${ }^{13}$ In South Korea a total of $399 \mathrm{MM}$ cases were identified from 2001 to 2010 (264 men and 135 women with a F/M ratio of 0.51$).^{24}$ The relatively high proportion of female cases of mesothelioma in South Korea has been discussed with regard to the environmental exposure to asbestos and to the relevant female workforce in asbestos textile factories in the 1970s and 1980s.

By performing international ecological comparisons, it is remarkable that a clear and significant correlation has been found between the proportion of female mesothelioma deaths and the overall mortality rate. In countries with higher mortality for pleural mesothelioma, reflecting in turn a greater level of asbestos use for industrial activities in the past, such as the UK, Australia and several Western European countries, a lower F/M ratio is actually observed. Conversely, in South American countries, Turkey and Eastern European countries a high proportion of female MM deaths is associated with relatively low MM total mortality rates. This finding seems to indicate that the higher was the industrial use of asbestos in the past, entailing mostly male-dominated workforces highly exposed to asbestos, the lower is the female share in mesothelioma occurrence. However, this interpretation must be considered with caution because of the possible underestimation of mesothelioma deaths due to diagnosis misclassification in low-mortality countries. In fact, a rare and difficult-to-diagnose disease such as mesothelioma can be underreported in mortality statistics. ${ }^{2}$ Moreover, despite the increasing number of countries reporting data to WHO, our analysis allows a limited representation or worldwide pleural mesothelioma mortality due to the absence of data from populous and industrially emerging countries such as China, India and Indonesia ${ }^{25}$ and from low-income countries as well.

Looking at the specific Italian situation it emerges indeed that Italy shows an outlier profile within the international context, as depicted by ecological figures, having a percentage of female MM deaths higher than expected from the regression model. The availability of clinical and exposure information about MM incident cases occurring in the past decades from ReNaM can help in providing some possible explanations.

Some limitations of the ReNaM dataset have to be discussed preliminarily. At the present, ReNaM is collecting MM cases in the whole of Italy, but activity of regional operating centres did not begin at the same time and this could have biased our study given the unhomogeneous territorial distribution of the sources of asbestos exposure (plants or environmental contamination sites). The ability and the effectiveness in identifying the modalities of asbestos exposure, despite the use of a shared structured questionnaire, is not fully consistent and the percentage of collected exposure histories varies between $45 \%$ and $95 \%$ among regions. Furthermore, the possible lack of homogeneity among CORs in classifying and coding diagnoses and exposures (according to the National Guidelines) is a crucial and real concern.

The modality of asbestos exposure is the most relevant variable associated with gender ratio variation in $\mathrm{ReNaM}$ data. Occupational exposure is documented in a wide variety of sectors for 
female incident mesothelioma cases, that include traditional activities with a direct use of asbestos, but also those with indirect exposures related to the presence of asbestos in structural frameworks and machinery at workplaces. In Italy (particularly in Piedmont, north-western Italy) many asbestos- processing plants, with a relevant female workforce, were active in the past. However, it must be underlined that the high occurrence of mesothelioma cases in women employed in non-asbestos textile industries, which emerge as the most common economic activity associated with occupational mesothelioma among women at the individual level, as also reported in other studies. ${ }^{11}$ Occupational exposures in this sector is mainly due to the widespread use of operating machines with asbestos containing friction materials since the 1950s. Asbestos materials were also applied to ceilings and walls of factories in order to avoid both condensation of steam and reflection of noise and used to insulate the steam pipelines and some parts of the ironing equipment. ${ }^{26} 27$ Italy was, especially in the past, one of the leading producers and exporters of textiles and wearing products worldwide, so explaining in part the high occurrence of $\mathrm{MM}$ in women in this country. However, it must be noticed that the proportion of female MM-defined cases attributed to occupation in the ReNaM database is about 33\%, most of ill women having experienced other modalities of asbestos exposure or remaining even with no causal definition. Furthermore, it is remarkable that a lower percentage of female MM cases were investigated for exposure by direct interview with respect to males and this could have affected the reliability of retrieved information that is evidently higher for direct interview.

For female MM cases a possible source of exposure has been acknowledged in soiled work clothes brought home by occupationally exposed relatives. ${ }^{28}$ In Italy, the cohort study of wives of Casale Monferrato asbestos-cement factory workers found a high excess of deaths for pleural mesothelioma (standardised mortality ratio, $\mathrm{SMR}=18.00,21$ observed vs 1.2 expected). ${ }^{29}$ A female predominance has been reported among not occupationally exposed MM cases detected by ReNaM in the period of incidence 1993 to 2008, women accounting for about 57\% of environmental and up to $85 \%$ of familial cases. ${ }^{30}$ The current analysis confirms the fundamental role of non-occupational exposure, and mainly of familial exposure in causing $\mathrm{MM}$ in women.

The gender ratio does not change over time during the incidence period, likely reflecting an exposure situation remaining almost stable until the 1990s in Italy. On the other hand, some regional differences in $\mathrm{F} / \mathrm{M}$ ratio are present over the national territory as reported in previous papers. For Biancavilla (Sicily) the modality of exposure to fluoro-edenite (asbestos-like fibrous mineral) is strictly environmental (due to diffuse pollution deriving from a nearby contaminated basalt quarry). ${ }^{31}$ Among women resident in Broni and Stradella (Lombardy), as well as for Casale Monferrato (Piedmont) both environmental and familial exposures contribute to the female mesothelioma clusters, attributable to large asbestos cement plants being active in the two areas from the first decades of the twentieth century. ${ }^{29} 32$ The concentration of mesothelioma cases in women in the municipalities of Grugliasco, Collegno, Rivoli, Ciriè and Nole, in Piedmont is mainly related to the presence of asbestos processing plants, employing in the past a number of female blue collar workers and causing familial exposure in many women resident in those areas and/or married with asbestos blue collar male workers. It includes one plant manufacturing asbestos textiles, asbestos-rubber and asbestos paper in Grugliasco, one asbestos textile plant in Nole and two plants manufacturing asbestos-containing brakes and clutches respectively in Grugliasco and in Nole. In Sarnico (Lombardy) a unique situation was documented where a non-asbestos textile industry was operating adjacent to an asbestos textile plant that shared the neighbouring area. ${ }^{33}$ For the above-mentioned municipalities having in their proximity industrial sources of asbestos causing occupational and non-occupational relevant exposures a $\mathrm{F} / \mathrm{M}$ ratio significantly higher than the national value was found, as well as for the town of Biancavilla, suffering a diffuse environmental contamination from natural sources of the above mentioned fluoro-edenite. The case is very different for three other municipalities (Monfalcone in Friuli-Venezia Giulia; Genova and La Spezia in Liguria) where asbestos exposure mainly occurred in men working in shipyards and oil refinery plants and only secondarily in the resident women due to cohabitation with an occupationally exposed worker. $^{34} 35$

Other characteristics of malignant mesothelioma in women have to be discussed for their interest for epidemiology, risk prevention strategies definition and compensation issues. In our analysis a lower percentage of women was found among pleural cases with fibrous or biphasic morphology $(\mathrm{F} / \mathrm{M}=0.25$ and 0.31 respectively) but an exhaustive interpretation of this evidence is difficult at this stage of the analysis. The percentage of women among peritoneal MM cases is $41.3 \%$ in the ReNaM dataset, with a gender ratio lower than for the pleural site. The diagnosis of peritoneal MM still suffers from poor sensitivity and specificity, and the misdiagnosis can be particularly high in women with abdominal neoplasms, when primary peritoneal serous carcinoma must be differentiated from ovarian serous carcinoma. $^{36}$ Recently an Italian population-based mortality study reported a gender ratio for peritoneal mesothelioma of 0.67 female cases for each male case and the authors discussed a possible elevated susceptibility of the peritoneal mesothelium in women to the carcinogenic effect of asbestos. ${ }^{19}$ Female MM cases showed an older age at diagnosis with respect to males ones, both among occupationally and not occupationally exposed subjects, confirming previous observations. ${ }^{12}$ A median latency of 50 years after the beginning of exposure is calculated in female pleural mesothelioma cases, but the descriptive design of our study prevents statistical inferences on the association between exposure and time to event (age or latency). ${ }^{37}$

Mesothelioma is a neoplasm having a very high occupational and environmental attributable fraction and is a well-known occupational disease. Nevertheless, studies that compared data from epidemiological surveillance and insurance systems, demonstrated a still concerning lack of awareness by affected people. In Italy the relative risk of not seeking compensation for women suffering from mesothelioma of occupational origin has been estimated significantly higher with respect to men $(1.7 ; \mathrm{p}<0.05) .{ }^{16}$ A more diffuse and accurate information about the causal role of asbestos exposure and increased efforts to recognise occupational origin are recommended in women. ${ }^{38}$

In conclusion our study provides evidence of a consistent proportion of mesothelioma cases occurring in women in Italy. The reasons for such a figure are the relevant role of non-occupational asbestos exposures accounting for almost 30\% of female cases investigated for exposure; and the historical presence of a relevant female workforce in the non-asbestos textile industry as well in various asbestos-containing product manufacturing industries. The great variety of jobs and domestic conditions potentially involved in asbestos exposure and the consequent difficulties in identifying occupational exposure and seeking compensation among women suggest the need to implement the tools (specifically the anamnestic questionnaire) to investigate 
the modalities of exposure in a gender perspective. Enhancing the awareness of occupational or environmental origin of mesothelioma in women by clinicians and healthcare operators could support the effectiveness of the insurance and welfare system, and benefit the exposure risks prevention policies.

\section{Author affiliations}

'Occupational and Environmental Medicine, Epidemiology and Hygiene Department, Italian Workers' Compensation Authority (INAIL), Rome, Italy

'Valle d'Aosta Health Local Unit, Regional Operating Centre of Valle d'Aosta (COR Valle d'Aosta), Aosta, Italy

${ }^{3}$ COR Piedmont, Unit of Cancer Prevention, University of Turin and CPO-Piemonte, Torino, Italy

${ }^{4}$ COR Liguria, UO Epidemiology, IRCCS Az, Ospedaliera Universitaria San Martino, National Cancer Research Institute (IST), Genova, Italy

${ }^{5}$ COR Lombardy, Department of Preventive Medicine, Fondazione IRCCS Ca' Granda, Ospedale Maggiore Policlinico and University of Milan, Milano, Italy

${ }^{6}$ Provincial Unit of Health, Hygiene and Occupational Medicine, COR Province of Trento, Trento, Italy

${ }^{7}$ Alto Adige Health Local Unit, COR Province of Bolzano, Bolzano, Italy

${ }^{8}$ Occupational Health Unit, Department of Prevention, COR Veneto, Padua, Italy

${ }^{9} \mathrm{Clinical}$ Unit of Occupational Medicine, COR Friuli-Venezia Giulia, University of

Trieste - Trieste General Hospitals, Trieste, Italy

${ }^{10}$ Health Local Unit, Public Health Department, COR Emilia-Romagna, Reggio Emilia, Italy

${ }^{11}$ Unit of Environmental and Occupational Epidemiology, COR Tuscany, Cancer Prevention and Research Institute, Firenze, Italy

${ }^{12}$ Cancer Prevention and Research Institute, Firenze, Italy

${ }^{13}$ Hygienistic, Environmental and Health Sciences Department, School of Sciences of the drug and the products of health, COR Marche, University of Camerino, Camerino, Italy

${ }^{14}$ Department of Hygiene and Public Health, COR Umbria, University of Perugia, Perugia, Italy

${ }^{15}$ Department of Epidemiology, COR Lazio, Lazio Region, Rome, Italy

${ }^{16}$ Department of Experimental Medicine, COR Lazio, University La Sapienza, Rome, Italy

${ }^{17}$ Health Local Unit, Occupational Medicine Unit, COR Abruzzo, Pescara, Italy

${ }^{18}$ Oncology Unit, COR Molise, Cardarelli Hospital, Campobasso, Italy

${ }^{19}$ Department of Experimental Medicine, COR Campania, Second University of Naples, Napoli, Italy

${ }^{20}$ Department of Interdisciplinary Medicine, Section of Occupational Medicine 'B. Ramazzini', COR Puglia, University of Bari, Firenze, Italy

${ }^{21}$ COR Basilicata, Epidemiologic Regional Centre, Potenza, Italy

${ }^{22}$ Public Health Unit, COR Calabria, Crotone, Italy

${ }^{23}$ Cancer Registry ASP Ragusa and Sicily Regional Epidemiological Observatory, COR Sicily, Policlinico, Italy

${ }^{24}$ COR Sardegna, Regional Epidemiological Centre, Cagliari, Italy

Collaborators Detragiache E (Regional Operating Centre of Valle d'Aosta (COR Valle d'Aosta), Valle d'Aosta Health Local Unit, Aosta, Italy); Merletti F, Gangemi M, Stura A, Brentisci C, Cammarieri Diglio G, Macerata V, Gilardetti M (COR Piedmont, Unit of Cancer Prevention, University of Turin and CPO-Piemonte, Torino, Italy); Lazzarotto A, Benfatto L, Bianchelli M, Mazzucco G, Campi MG, Malacarne D, Camposeragno D, Di Giorgio F, Canessa PA (COR Liguria, UO Epidemiology, IRCCS Az. Ospedaliera Universitaria San Martino, National Cancer Research Institute (IST), Genova, Italy); Consonni D, Pesatori AC, Riboldi L (COR Lombardy, Department of Preventive Medicine, Fondazione IRCCS Ca' Granda, Ospedale Maggiore Policlinico and University of Milan, Milano, Italy); Bressan V, Gioffrè, Ballarin M (COR Veneto, Occupational Health Unit, Department of Prevention, Padua, Italy); Chermaz C, De Michieli P (COR Friuli-Venezia Giulia, University of Trieste -Trieste General Hospitals, Clinical Unit of Occupational Medicine, Trieste, Italy); Mangone L, Storchi C, Sala O (COR Emilia-Romagna, Health Local Unit, Public Health Department, Reggio Emilia, Italy); Badiali AM, Cacciarini V, Giovannetti L, Martini A(COR Tuscany, Cancer Prevention and Research Institute, Unit of Environmental and Occupational Epidemiology, Firenze, Italy); Grappasonni I(COR Marche, University of Camerino, Hygienistic, Environmental and Health Sciences Department, School of Sciences of the drug and the products of health, Camerino, Italy); Masanotti G, D'Alo' D, Petrucci MS (COR Umbria, University of Perugia, Department of Hygiene and Public Health, Perugia, Italy); Davoli M, Forastiere F, Cavariani F, Ancona L (COR Lazio, University La Sapienza, Department of Experimental Medicine, Roma, Italy); Di Giammarco A (COR Abruzzo, Health Local Unit, Occupational Medicine Unit, Pescara, Italy); Menegozzo S, Canfora ML, Santoro M, Viscardi F, Brangi A, Cozza V (COR Campania, Second University of Naples, Department of Experimental Medicine, Napoli, Italy); Vimercati L
(COR Puglia, University of Bari, Department of Interdisciplinary Medicine, Section of Occupational Medicine 'B.Ramazzini" Bari, Italy); Lio SG (COR Calabria, Public Health Unit, Crotone, Italy); Cascone G, Frasca G, Giurdanella MC, Martorana C, Nicita C, Rollo P, Spata E, Dardanoni G, Scondotto S (COR Sicily, Cancer Registry ASP Ragusa and Sicily Regional Epidemiological Observatory, Italy); Nieddu V, Pergola M, Stecchi S (COR Sardegna. Regional Epidemiological Centre, Cagliari, Italy).

Contributors AM designed the study, performed statistical analyses, interpreted the data and drafted the manuscript, $A B, M C, D D, A S$, PF participated in performing statistical analyses and in interpreting the data, SI participated in designing the study and interpreting the data, MV, DM, VG, CM, GS, GM, EM, PG, CN, FD, AR, EC, SS, CP, $R C, F S, E R, V A, L T, I A, D C, G C, F T, R T$, MM collected data, defined asbestos exposure. All authors participated in revising the manuscript.

Funding This research was supported and founded by INAIL (Italian Workers Compensation Authority). The units of epidemiology or occupational health hosting the Regional Operating Centres belong to the National Health Service and are financed by their health authorities.

Competing interests The following authors reported that they have served as expert witness for the public prosecutor in court trials on asbestos-related diseases: EM, DM, SS, VG, CM, RC.

\section{Patient consent Obtained.}

Provenance and peer review Not commissioned; externally peer reviewed.

Open Access This is an Open Access article distributed in accordance with the Creative Commons Attribution Non Commercial (CC BY-NC 4.0) license, which permits others to distribute, remix, adapt, build upon this work non-commercially, and license their derivative works on different terms, provided the original work is properly cited and the use is non-commercial. See: http://creativecommons.org/ licenses/by-nc/4.0/

(c) Article author(s) (or their employer(s) unless otherwise stated in the text of the article) 2018. All rights reserved. No commercial use is permitted unless otherwise expressly granted.

\section{REFERENCES}

1 Straif $K$, Benbrahim-Tallaa $L$, Baan $R$, et al. A review of human carcinogens-Part $C$ metals, arsenic, dusts, and fibres. Lancet Oncol 2009:10:453-4.

2 Park EK, Takahashi K, Hoshuyama T, et al. Global magnitude of reported and unreported mesothelioma. Environ Health Perspect 2011:119:514-8.

3 WHO. Elimination of asbestos-related diseases. Geneva: World Health Organization, 2006. http://www.who.int/occupational_health/publications/asbestosrelateddiseases. pdf

4 Marinaccio A, Binazzi A, Marzio DD, et al. Pleural malignant mesothelioma epidemic: incidence, modalities of asbestos exposure and occupations involved from the Italian National Register. Int J Cancer 2012;130:2146-54.

5 Lacourt A, Gramond C, Rolland P, et al. Occupational and non-occupational attributable risk of asbestos exposure for malignant pleural mesothelioma. Thorax 2014:69:532-9.

6 Reid A, Berry G, de Klerk N, et al. Age and sex differences in malignant mesothelioma after residential exposure to blue asbestos (crocidolite). Chest 2007:131:376-82.

7 Berk S, Yalcin H, Dogan OT, et al. The assessment of the malignant mesothelioma cases and environmental asbestos exposure in sivas province, Turkey. Environ Geochem Health 2014;36:55-64.

8 Goldberg S, Rey G, Luce D, et al. Possible effect of environmental exposure to asbestos on geographical variation in mesothelioma rates. Occup Environ Med 2010;67:417-21

9 Soeberg MJ, Leigh J, Driscoll T, et al. Incidence and survival trends for malignant pleural and peritoneal mesothelioma, Australia, 1982-2009. Occup Environ Med 2016:73:187-94.

10 Järvholm B, Burdorf $A$. Emerging evidence that the ban on asbestos use is reducing the occurrence of pleural mesothelioma in Sweden. Scand J Public Health 2015;43:875-81.

11 Hyland RA, Ware S, Johnson AR, et al. Incidence trends and gender differences in malignant mesothelioma in New South Wales, Australia. Scand J Work Environ Health 2007:33:286-92.

12 Rake C, Gilham C, Hatch J, et al. Occupational, domestic and environmental mesothelioma risks in the British population: a case-control study. $\mathrm{Br} J$ Cancer 2009:100:1175-83.

13 Camiade E, Gramond C, Jutand MA, et al. Characterization of a French series of female cases of mesothelioma. Am J Ind Med 2013;56:n/a-16.

14 Langhoff MD, Kragh-Thomsen MB, Stanislaus S, et al. Almost half of women with malignant mesothelioma were exposed to asbestos at home through their husbands or sons. Dan Med J 2014;61:A4902.

15 Merler E, Bressan V, Bilato AM, et al. [The effectiveness of compensation system for mesotheliomas due to occupational exposure to asbestos and determinants for requests and awards: an evaluation based on record-linkage between the Veneto 
Mesothelioma Register and the claims and compensations recorded by the National Insurance Institute (INAIL)]. Epidemiol Prev 2011:35:331-8.

16 Marinaccio A, Scarselli A, Merler E, et al. Mesothelioma incidence surveillance systems and claims for workers' compensation. Epidemiological evidence and prospects for an integrated framework. BMC Public Health 2012;12:314.

17 Marinaccio A, Binazzi A, Cauzillo G, et al. Analysis of latency time and its determinants in asbestos related malignant mesothelioma cases of the Italian register. Eur J Cancer 2007:43:2722-8.

18 Nesti M, Adamoli S, Ammirabile F, et al. eds. Linee guida per la rilevazione e la definizione dei casi di mesotelioma maligno e la trasmissione delle informazioni all'ISPESL da parte dei centri operativi regionali. Roma: Monografia ISPESL, 2003.

19 Conti S, Minelli G, Ascoli V, et al. Peritoneal mesothelioma in Italy: trends and geography of mortality and incidence. Am J Ind Med 2015;58:1050-8.

20 Marinaccio A, Binazzi A, Bonafede M et al, eds. /l Registro Nazionale dei Mesoteliomi (ReNaM). Quinto Rapporto. Roma: Monografia INAIL, 2015. Italian.

21 Fleiss JL, Levin B, Paik MC. Statistical methods for rates and proportions. 3rd edn: John Wiley \& Sons, Inc., 2003.

22 Ferrante $P$, Binazzi A, Branchi C, et al. National epidemiological surveillance systems of mesothelioma cases Epidemiol Prev. 2016:40:215-23.

23 Australian Mesothelioma Registry. 4th report. Safe work Australia. 2015 http://www. mesothelioma-australia.com/publications-and-data/publications

24 Jung SH, Kim HR, Koh SB, et al. A decade of malignant mesothelioma surveillance in Korea. Am J Ind Med 2012;55:869-75.

25 Bianchi C, Bianchi T. Malignant mesothelioma: global incidence and relationship with asbestos. Ind Health 2007;45:379-87.

26 Barbieri PG, Somigliana A, Girelli R, et al. [Malignant mesothelioma in garment sewing-machine workers]. Med Lav 2008;99:187-93.

27 Chiappino G, Mensi C, Riboldi L, et al. [Asbestos risk in the textile industry: final confirmation of data from the Lombardy Mesothelioma Registry]. Med Lav 2003;94:521-30.
28 Goswami E, Craven V, Dahlstrom DL, et al. Domestic asbestos exposure: a review of epidemiologic and exposure data. Int J Environ Res Public Health 2013;10:5629-70

29 Ferrante $\mathrm{D}$, Bertolotti M, Todesco A, et al. Cancer mortality and incidence of mesothelioma in a cohort of wives of asbestos workers in Casale Monferrato, Italy. Environ Health Perspect 2007;115:1401-5.

30 Marinaccio A, Binazzi A, Bonafede M, et al. Malignant mesothelioma due to non-occupational asbestos exposure from the Italian national surveillance system (ReNaM): epidemiology and public health issues. Occup Environ Med 2015;72:648-55.

31 Bruno C, Tumino R, Fazzo L, et al. Incidence of pleural mesothelioma in a community exposed to fibres with fluoro-edenitic composition in Biancavilla (Sicily, Italy). Ann Ist Super Sanita 2014:50:111-8.

32 Mensi C, Riboldi L, De Matteis S, et al. Impact of an asbestos cement factory on mesothelioma incidence: global assessment of effects of occupational, familial, and environmental exposure. Environ Int 2015;74:191-9.

33 Barbieri PG, Somigliana A, Caironi M, et al. [The epidemiologic surveillance of malignant mesothelioma in the Lower Iseo Lake area]. Epidemiol Prev 2007:31(4 Suppl 1):16-22.

34 Dodoli D, Del Nevo M, Fiumalbi C, et al. Environmental household exposures to asbestos and occurrence of pleural mesothelioma. Am J Ind Med 1992:21:681-7.

35 Gennaro V, Ugolini D, Viarengo P, et al. Incidence of pleural mesothelioma in Liguria Region, Italy (1996-2002). Eur J Cancer 2005;41:2709-14.

36 Clement PB. Selected miscellaneous ovarian lesions: small cell carcinomas, mesothelia lesions, mesenchymal and mixed neoplasms, and non-neoplastic lesions. Mod Pathol 2005;18 Suppl 2:S113-S129.

37 Consonni D. [Something is missing: what's wrong with using age at diagnosis/death or latency among cases]. Epidemiol Prev 2013:37:85-8.

38 Anthonisen NR. Workers' compensation and mesothelioma. Can Respir J 2009;16:146-7. 